\section{Preparation of Underrepresented Males for Scientific Careers: A Study of the Dr. John H. Hopps Jr. Defense Research Scholars Program at Morehouse College}

\author{
Rahmelle C. Thompson, ${ }^{\dagger}$ Thema Monroe-White, ${ }^{\neq *}$ Jeffrey Xavier," \\ Courtney Howell, ${ }^{\ddagger}$ Myisha Roberson Moore, ${ }^{\dagger}$ and J. K. Haynes $\$$ \\ ${ }^{\dagger}$ Hopps Defense Research Scholars Program and "Department of Biology, Morehouse College, \\ Atlanta, GA 30314; ; $5 a g e F o x$ Consulting Group, Atlanta, GA 30307; "SageFox Consulting Group, \\ Amherst, MA 01002
}

\begin{abstract}
Equal representation within higher education science, technology, engineering, and mathematics (STEM) fields and the STEM workforce in the United States across demographically diverse populations is a long-standing challenge. This study uses two-to-one nearest-neighbor matched-comparison group design to examine academic achievement, pursuit of graduate science degree, and classification of graduate institution attended by students participating in the Hopps Scholars Program (Hopps) at Morehouse College. Hopps is a highly structured enrichment program aimed at increasing participation of black males in STEM fields. Morehouse institutional records, Hopps Program records, and National Student Clearinghouse data were used to examine differences between Hopps and non-Hopps STEM graduates of Morehouse. Two-way sample $t$ tests and chi-square tests revealed significant differences in academic achievement, likelihood of STEM degree pursuit, and the classification of graduate institutions attended by Hopps versus non-Hopps students. Hopps Scholars were significantly more likely than non-Hopps STEM graduates both to pursue STEM doctoral degrees and to attend doctoral-granting institutions with higher research activity. The Hopps Program's approach to training black male students for scientific careers is a model of success for other programs committed to increasing the number of black males pursuing advanced degrees in STEM.
\end{abstract}

\section{INTRODUCTION}

The under- and overrepresentation of certain demographic populations in science, technology, engineering, and mathematics (STEM) and in education more broadly has been discussed for a long period of time (Coleman, 1968). This issue of underrepresentation is of particular concern, as underrepresented students are not pursuing STEM careers in sufficient numbers to satisfy the needs of an increasingly technology-based economy (Chang et al., 2008; President's Council of Advisors on Science and Technology, 2012; Allen-Ramdial and Campbell, 2014). In the near future, African Americans and Hispanics/Latinos will represent a larger proportion of the population than they do now, and a diverse scientific and engineering workforce will become increasingly necessary to benefit society's broadening economic and competitive interests (May and Chubin, 2003; Chubin et al., 2005; McSherry, 2005; Pender et al., 2010).

However, the shortage of qualified and talented students in STEM fields does not appear to be due to lack of interest on the part of these students. It has been well documented that underrepresented students such as African Americans and Hispanics/ Latinos tend to enroll in STEM fields in college at the same rate as their white and Asian counterparts; however, they are much less likely to complete their courses of
Kenneth Gibbs Monitoring Editor Submitted December 30, 2015; Revised June 16, 2016; Accepted June 16, 2016

CBE Life Sci Educ September 1, 2016 15:ar40 DOI:10.1187/cbe.15-12-0263

*Address correspondence to: Thema MonroeWhite (t.monroe.white@gmail.com)

(c) 2016 R. C. Thompson et al. CBE-Life Sciences Education @ 2016 The American Society for Cell Biology. This article is distributed by The American Society for Cell Biology under license from the author(s). It is available to the public under an Attribution-Noncommercial-Share Alike 3.0 Unported Creative Commons License (http://creativecommons.org/licenses/ by-nc-sa/3.0)

"ASCB®" and "The American Society for Cell Biology $\circledR^{\prime \prime}$ are registered trademarks of The American Society for Cell Biology. 
study (Anderson and Kim, 2006; Leggon and Pearson, 2008; National Academy of Sciences, National Academy of Engineering, and Institute of Medicine, 2011; Chang et al., 2014). Studies indicate that this attrition steadily progresses through academic pathways in the sciences, resulting in a very small number of individuals from underrepresented racial and ethnic backgrounds emerging with advanced degrees in STEM fields (Carter et al., 2009; Pender et al., 2010).

Historically black colleges and universities (HBCUs) have made substantial contributions toward addressing this gap (Owens et al., 2012). Notably, among known U.S. baccalaureate-origin institutions of 1997-2006 black science and engineering doctoral recipients, the top eight were HBCUs (National Science Foundation, National Center for Science and Engineering Statistics [NSF, NCES], 2015).

Several studies have demonstrated the impact of STEM-based interventions on the recruitment and retention of underrepresented students in STEM. However, whether these interventions are housed at predominantly white institutions (PWIs; Maton et al., 2012; Toven-Lindsey et al., 2015) or "minority"-serving institutions (MSIs; Kendricks et al., 2013; Fakayode et al., 2014), many of these studies primarily focus on undergraduate outcomes (i.e., cumulative grade point average [GPA], STEM GPA, and/or graduation rates), as opposed to persistence to graduate school. On the other hand, while large-scale, multi-institutional studies have investigated the retention of underrepresented STEM students from undergraduate to graduate school (Myers and Pavel, 2011; Schultz et al., 2011), these summative, aggregate analyses do not differentiate between baccalaureate-origin institution types.

Fortunately, there is a growing literature on STEM recruitment, retention, and graduation of undergraduate students at institutions with significant ( $>50 \%$ ) underrepresented student populations (e.g., HBCUs); however, most of these studies are qualitative (Perna et al., 2010; Burrell et al., 2015; Nguyen, 2015) or do not investigate patterns of persistence beyond undergraduate STEM graduation. This study fills an important gap in the literature by presenting a quantitative examination of graduate school retention patterns of an HBCU-based STEM intervention effort at Morehouse College, one of the top baccalaureate-origin institutions of black science and engineering doctoral recipients (Burrelli and Rapoport, 2008; NSF, NCES, 2015).

\section{Prior Factors of Successful STEM-Based Interventions}

A variety of intervention programs have been funded by the federal government and other sources to improve outcomes for the underrepresented majority of college students by addressing many of the challenges these students face. ${ }^{1}$ Some key components of these programs include: financial aid, peerto-peer study groups, academic advisement, faculty mentoring, research opportunities, and internship opportunities (Nagda et al., 1998; Campbell et al., 2002; Maton and Hrabowski, 2004; Jones et al., 2010). Research experiences are thought to be especially powerful and transformative, as they enable students to work with peers and faculty in a "hands-on" environment and to learn to identify themselves as

${ }^{1}$ Approximately 70 percent of college students are women or members of ethnically marginalized groups, but they receive only 45\% of STEM degrees; see President's Council of Advisors on Science and Technology, 2012. scientists (Hunter et al., 2007; Russell et al., 2007; Jones et al., 2010; Pender et al., 2010; Eagan et al., 2013).

Maton et al. (2012) identify the following key factors in enhancing the success of underrepresented students in STEM fields:

- Promote academic and social integration, as students of color are more likely to experience social and academic isolation on campuses and in STEM fields in which whites are overrepresented. (Fries-Britt, 2000; Cole and Barber, 2003; National Academy of Sciences, National Academy of Engineering, and Institute of Medicine, 2011).

- Reinforce mastery of subject material and skills that are critical to success in STEM, such as time management, analytical problem-solving, effective study habits, and the ability to take advantage of existing campus resources (Gándara and Maxwell-Jolly, 1999; Gordon and Bridglall, 2004; National Academy of Sciences, National Academy of Engineering, and Institute of Medicine, 2011).

- Motivate success by establishing a culture of high faculty expectations, and provide support to students through academically supportive peer networks and financial assistance (Seymour and Hewitt, 2000; May and Chubin, 2003; National Academy of Sciences, National Academy of Engineering, and Institute of Medicine, 2011).

- Provide ongoing monitoring to help guide students through difficult decision-making processes; advising to enable students to receive feedback on their strengths and weaknesses; and guidance on academic and career goals in STEM (Seymour and Hewitt, 2000; Gándara and Maxwell-Jolly, 1999; National Academy of Sciences, National Academy of Engineering, and Institute of Medicine, 2011).

\section{The Dr. John H. Hopps Jr. Defense Research Scholars Program}

The design of the Dr. John H. Hopps Jr. Defense Research Scholars Program (Hopps) is grounded in the aforementioned key factors in enhancing the success of underrepresented students in STEM fields. The program, which began in 2006, was named after Dr. John H. Hopps Jr., a former provost of Morehouse College and a former leader at the Department of Defense. Its overarching goal is to produce "a critical mass of underrepresented minority males who will perform at the highest level of academic achievement in the scientific realm" 2 and to mitigate the disparity between the relatively large percentage of the U.S. population who identifies as an underrepresented majority group and the small percentage of graduate degrees they earn, particularly in STEM fields. To achieve this goal, Hopps was structured around four major objectives:

1. Develop a cadre of competitive underrepresented male students in scientific research.

2. Prepare students for admission into top-tier graduate programs in STEM.

3. Increase the number of Morehouse graduates pursuing graduate school by $50 \%$.

4. Enhance Morehouse students' participation in scholarly scientific activities that include professional presentations,

${ }^{2}$ From www.hoppsscholars.com (accessed 24 November 2015). 
scholarly manuscripts/publications, and multidisciplinary initiatives that are research-based.

The Hopps Program followed closely after the Packard Scholars Program, an earlier Morehouse Division of Science and Mathematics Program designed to encourage students to pursue graduate school in STEM majors. In 1999, Morehouse received a grant from the David and Lucile Packard Foundation to establish the Division of Science and Mathematics and the Packard Scholars Program. The funding provided for the recruitment of two classes of Packard Scholars. That program successfully recruited 18-20 students per year in science and mathematics, providing them with funds to cover the cost of tuition and expenses through graduation. Scholars were recruited directly out of high school and were exposed to research and course work throughout their tenure. The design of Hopps also borrowed from the highly successful Meyerhoff Scholars Program at the University of Maryland, Baltimore County (Hrabowski and Maton, 1995; Maton et al., 2007). The major features of Hopps are outlined in the following sections.

Summer Pre-Freshman Program. An 8-week program for incoming freshmen, wherein students were exposed to crucial courses such as critical thinking, English, and calculus. Group research projects were conducted in various STEM laboratories. This program also included field trips to local science museums and visits to NASA and the Kennedy Space Center.

\section{Mentored Research Experiences}

Academic-Year Research. Students were required to conduct 10-15 h per week of research during the academic year. During the first semester of their freshman year, they were asked to identify a research mentor in whose laboratory they were interested in working. Research laboratories in the four Atlanta University Center Consortium colleges (Clark Atlanta University, Spelman College, Morehouse College, and Morehouse School of Medicine) and in other local universities were used. During the second semester of their freshman year, students were expected to begin conducting research.

Summer Research. During the summer, scholars conducted external and internal research at multiple national and international locations, including Harvard University, Georgia Institute of Technology, and the University of São Paulo, Brazil. Students were responsible for identifying their summer research mentors (with guidance from program staff) and often sought out research opportunities at institutions they were considering for graduate school. Hopps Scholars were also required to spend at least one summer conducting research in a Department of Defense-funded laboratory.

Program Meetings. Scholars were required to attend weekly meetings. Speakers were invited to present their research and talk about their academic and career paths in STEM. Program staff also alerted students to upcoming opportunities (application deadlines, conference opportunities, etc.). Scholars also presented their own academic-year and/or summer research to hone their oral presentation skills.

Graduate School Tours and Laboratory Site Visits. Scholars participated in tours of graduate schools and laboratories around the country. The availability of locations was facilitated by the principal investigators' and director's strong relationships with many schools and Morehouse College's strong ties with its alumni. During these tours, students were encouraged not only to identify potential research mentors and institutions that would facilitate their success, but also to work on their own networking skills.

Program Coaching and Counseling Support. Hopps included a strong emphasis on increasing students' confidence in STEM-related pursuits and their ability to advocate for their own personal interests when selecting their path by communicating with faculty members and other decision makers. The program also sought to foster a strong sense of identity and belonging within the STEM community. Through coaching and support from Hopps leadership and other staff, students were supported in their pursuits and were also monitored to ensure that their grades allowed them to continue to meet their goals.

Scientific Conference and Symposia Support. Beginning in the fall of their sophomore year and every year thereafter, Scholars were required to present their research at national conferences. Scholars were also required to present their research at the Annual Hopps Research Training Symposium held at Morehouse College. Faculty representatives from graduate schools across the nation were in attendance to provide critiques of the students' oral and poster presentations. The meaningful relationships that developed from these exchanges often led to additional constructive mentor advisement that continued throughout the students' matriculation in graduate school.

Financial Assistance. Hopps Scholars were given tuition assistance up to the full amount of Morehouse College's tuition and fees each semester of participation. Scholars were also provided annual travel funds for scientific conferences, annual funds for their research mentors to purchase research supplies, and, in later years of the program, stipends.

\section{Recruitment, Eligibility Requirements, and Continued Participation}

Competitive applicants to Hopps had a minimum 1200 Scholastic Aptitude Test (SAT) score (600 Mathematics; 600 English) or minimum ACT Scores of 27 Mathematics and 27 English, and a minimum high school GPA of 3.00. Students were considered for admission to Hopps based on their academic performance, standardized college admissions test scores, letters of support, prior research experience, and stated motivation and interest in pursuing a research career in a STEM discipline. Hopps Scholars were recruited for the Hopps summer program by telephoning or emailing STEM students who met the criteria for admission to the 4-year Hopps Program, after receiving a list of STEM admits from the Morehouse Admissions Office. Final admission to the four 4-year Hopps Program depended on their performance in the summer program and required them to achieve at least a "B" in the courses in which they were enrolled. Final admission to the 4-year Hopps Program was determined by a committee composed of STEM faculty and the program director. Admitted students were notified by telephone or email and by letter. All Scholars were expected to major in biology, chemistry, computer science, mathematics, physics, or engineering 
and to express a commitment to pursuing a $\mathrm{PhD}$ in a STEM field after graduation. To remain in the program, Scholars were required to maintain a $3.0 \mathrm{GPA}$, major in a STEM field, and continue to participate in the activities identified above.

\section{Research Questions}

This study ${ }^{3}$ aims to determine the extent to which significant differences between Hopps Scholars and non-Hopps students exist on a variety of indicators of academic STEM retention. Our research questions (RQs) reflect this objective:

- RQ1: To what extent have Hopps Scholars succeeded academically at Morehouse College at higher rates than a comparable group of non-Hopps Morehouse graduates?

- RQ2: To what extent have Hopps Scholars enrolled in graduate school programs in STEM at higher rates than a comparable group of non-Hopps Morehouse graduates?

- RQ3: To what extent have Hopps Scholars matriculated to graduate school in research-intensive institutions at higher rates than a comparable group of non-Hopps Morehouse graduates?

Multiple data sources are used to answer these questions. A description of the data preparation, variable construction, and analysis processes are outlined below along with findings.

\section{METHODS}

\section{Data Preparation}

Data used for this study came from three primary sources: the National Student Clearinghouse (NSC), the Provost's Office at Morehouse College, and program-level data from the Hopps Program. The NSC provided information on the postbaccalaureate academic work of Hopps Scholars for whom data were available. Included in the NSC data set were the names of the graduate institutions and enrollment status of Hopps graduates at those institutions. This data set was later expanded to include NSC data regarding all Morehouse College students who had graduated in STEM majors between 2005 and 2014. ${ }^{4}$ These data were divided into two sections, described below, and all Hopps students were identified using unique identifiers:

- Subsequent enrollment: All known schools and degree programs in which Morehouse STEM graduates had enrolled. This spreadsheet contained records of a total of 1405 students.

- Subsequent graduation: For the students detailed in the "subsequent enrollment" tab who had graduated, this sheet contained information about the schools from which they had graduated and the degree(s) obtained. A total of 492 students were described in this file.

The Provost's Office at Morehouse College provided weighted high school GPA scores, standardized test scores (SAT and ACT), Morehouse academic major, and cumulative Morehouse GPA on all 1405 Morehouse graduates who had been queried for the NSC data request. Program-level data from the Hopps Program principal investigator (PI) and director also

\footnotetext{
${ }^{3}$ This study was reviewed and approved by the Morehouse College Institutiona Review Board (1400700).

${ }^{4}$ Morehouse STEM majors include applied physics, biology, chemistry, computer science, general science, mathematics, physics, preengineering, and psychology.
}

provided detailed status information on all former Hopps Scholars. These data allowed us to distinguish between Scholars who graduated while still affiliated with the Hopps Program versus those who left and/or were removed from the Program.

Data were prepared for analysis and combined using Microsoft Excel Software such that a single record with all relevant information was associated with one, unique student identifier. All analyses were conducted using SPSS and/or R statistical package software.

\section{Variable Definition}

Scholar Status. Scholar status or type was determined using information provided by the program PI and director based largely on historic program records. These data revealed three types of former Hopps Scholars and a comparison group of nonHopps Morehouse STEM graduates.

- Non-Hopps Scholars are operationalized as all non-Hopps Morehouse STEM graduates.

- Hopps Scholars are defined as any student accepted to the Hopps Program who participated in the Program for at least one semester. This includes students who left and/or were removed from the program.

- Hopps Alumni are defined as Scholars who upon graduation from Morehouse were in good standing with the Hopps Program (i.e., receiving financial and/or programmatic support in their final semester).

- Hopps Participants are defined as Scholars who were accepted to the Hopps Program but did not remain in the program through graduation. There are two types of participants given this definition: Left and Removed. Participants who left the program are defined as Scholars who either requested to leave the program due to personal reasons or changes in academic/career interests or confessed to no longer being interested in research, and so on. Participants removed from the program were no longer supported by the Hopps Program for failure to meet continued participation requirements (i.e., academic performance, low levels of participation in research, etc.). On average, Participants who left and/or were removed from the program remained active Hopps Scholars for 1.5-2 years.

In addition to Scholar status, several outcomes were identified for inclusion in the analyses. Outcome variables were grouped into three classes: academic achievement, graduate school enrollment, and graduate institutional classification. We review each below.

\section{Academic Achievement}

- Academic achievement is measured in terms of overall Morehouse cumulative GPA. Cumulative Morehouse College GPA is operationalized on a 1.00-4.00 scale obtained from institutional data.

\section{Graduate Program Enrollment}

- Graduate program enrollment data were obtained from NSC records. The number of Morehouse STEM PhD graduates for whom data were available was too small to analyze $(n=3)$. This is understandable, as few 2010-2014 Morehouse graduates have had the opportunity to complete a terminal 
degree. Therefore, we used post-Morehouse enrollment in a graduate program as a proxy for Morehouse STEM graduates' persistence in STEM.

NSC data were gathered to track the enrollment of Hopps Scholars and non-Hopps Morehouse STEM students. However, not all advanced degrees are alike. Often, alumni with undergraduate STEM degrees pursue nonresearch careers, including medical or other health-related degrees. To determine whether Morehouse STEM graduates enrolled in 1) STEM PhD programs, 2) medical or health-related programs, or 3) other degree programs, the program fields variable from the NSC data set were classified using the STEM Classification of Instructional Programs (CIP) Crosswalk (see the Supplemental Material). It is important to note that this list does not include psychology as a STEM field; however, at the beginning of the Hopps Program, psychology was considered an eligible STEM major. For this reason, STEM graduate degrees and STEM graduate degrees including psychology have been reported separately. A preliminary review of the data revealed notable subclassifications worth distinguishing:

- Graduate program enrollment is measured as a dichotomous (yes/no) variable defined as having enrolled in a graduate degree program in any field.

- Graduate program enrollment in STEM: The graduate degree program enrollment variable was disaggregated to account for two types of STEM degrees: one in which psychology graduate degrees were included in STEM; and one in which they were not. It is measured as a dichotomous (yes/no) variable for having enrolled in a STEM graduate degree program. ${ }^{5}$

- Health-related program enrollment: Additionally, to verify that Hopps graduates were pursuing advanced $\mathrm{PhD}$ degrees in STEM and not other professional degrees (i.e., in medicine, dentistry, etc.), enrollment and graduation from health-related degree programs were also analyzed. This variable was constructed to determine whether Hopps Scholars were pursuing health-related degrees at similar rates as their non-Hopps counterparts. This variable is defined as a dichotomous (yes/no) variable for having enrolled in a health-related degree.

Institutional Classification. The Hopps Program stressed not only the importance of STEM retention among Hopps Scholars but also the importance of attending research-intensive/prestigious institutions. Toward this end, additional analyses were performed to gauge the extent to which Hopps Scholars were more likely to pursue advanced degrees within more research-intensive universities. The Carnegie Classification of Institutions of Higher Education identifies four types of doctoral-granting institutions, according to levels of research activity ${ }^{6}$ : master's (master's colleges and universities), DRU (doctoral/research

\footnotetext{
${ }^{5}$ NSF CIP codes were used to classify graduate degree programs as STEM (see the Supplemental Material for a complete list).

${ }^{6}$ Doctorate-granting universities include institutions that awarded at least 20 research doctoral degrees during the update year (excluding doctoral-level degrees that qualify recipients for entry into professional practice, such as the JD, MD, PharmD, and DPT). Master's colleges and universities generally include institutions that awarded at least 50 master's degrees and fewer than 20 doctoral degrees during the update year and exclude special focus institutions and tribal colleges.
}

universities; formerly classified as low research activity); RU/H (research universities: high research activity), and RU/VH (research universities: very high research activity). Our matched data set $(N=282)$ contained graduate institution names for 167 cases (i.e., Morehouse graduates). These institutions were coded and analyzed for significant differences using the Carnegie institutional ranking codes outlined above. ${ }^{7}$ In instances in which graduates attended more than one institution, the institution with the highest Carnegie research classification rank was used.

Defining a Comparison Group. To compare Hopps with nonHopps Morehouse graduates, we bound our data set to include only students who graduated between 2010 (the earliest date at which a Hopps Scholar graduated from Morehouse College) and 2014 (the latest information available). This ensured that Hopps Scholars were only compared with those with the same number of years between Morehouse graduation and graduate program enrollment/ completion. This reduced our sample from 1405 to 625 .

Reducing Selection Bias. Matching reduces selection (or recruitment) bias that could potentially prejudice our results by comparing the treatment unit (Hopps Scholar) with a comparison unit (non-Hopps Scholar) from the same general population. In this study, the matched comparison group was generated from the 2010-2014 sample of 625 Morehouse graduates. Matching involved the use of three key Hopps eligibility criteria: incoming STEM major, SAT score (math), and high school GPA. This method of defining a comparison group allowed us to compare the Hopps students with the entire Morehouse STEM population of similarly prepared students.

Nearest-Neighbor Propensity Score Matching (PSM). PSM using the Matchit package in RStudio software (RStudio Team, 2015) with nearest-neighbor two-to-one matching was used in Table 1 (Austin, 2010; Ho et al., 2011; Randolph et al., 2014). This nearest-neighbor technique matches a treated unit (Hopps Scholar) to a comparison unit (non-Hopps STEM student) that is closest in terms of a distance measure. Nearest-neighbor matching randomly sorts both the treatment and comparison units based on the absolute value of the difference between the propensity score of the treatment and comparison under consideration. The closest comparison is chosen as the match.

To conduct PSM using RStudio software, all cases must be complete (i.e., no missing information). Unfortunately, SAT Math scores and high school GPAs were not available for all graduates. Therefore, in instances in which high school GPA was missing, that particular unit (Morehouse graduate) was removed from the data set. In instances in which SAT Math scores were missing but ACT math scores were present, concordance tables were used to convert ACT Math scores to SAT I Math scores (Dorans, 1999, 2004). However, if both SAT Math and ACT Math scores were missing, that unit was also removed. This process reduced our data set to 468 (Hopps, $n=94$; nonHopps, $n=374$ ).

7http://carnegieclassifications.iu.edu/descriptions/basic.php (accessed 14 August 2015). 
TABLE 1. PSM results

\begin{tabular}{|c|c|c|c|c|c|c|c|}
\hline & $\begin{array}{l}\text { Means } \\
\text { treated }\end{array}$ & $\begin{array}{c}\text { Means } \\
\text { comparison }\end{array}$ & $\begin{array}{c}\text { SD } \\
\text { comparison }\end{array}$ & $\begin{array}{c}\text { Mean } \\
\text { difference }\end{array}$ & $\begin{array}{l}\text { eQQ } \\
\text { med }\end{array}$ & $\begin{array}{c}\mathrm{eQQ} \\
\text { mean }\end{array}$ & $\begin{array}{l}\mathrm{eQQ} \\
\max \end{array}$ \\
\hline \multicolumn{8}{|l|}{ Summary of balance for all data } \\
\hline Distance & 0.2800 & 0.1810 & 0.1223 & 0.0990 & 0.1045 & 0.0997 & 0.13 \\
\hline High school reported GPA & 3.6837 & 3.3924 & 0.5248 & 0.5248 & 0.3000 & 0.3134 & 1.25 \\
\hline SAT Math & 608.0851 & 546.9519 & 85.5314 & 61.1332 & 60.0000 & 61.5957 & 90.00 \\
\hline \multicolumn{8}{|c|}{ Summary of balance for matched data } \\
\hline Distance & 0.280 & 0.2632 & 0.1175 & 0.0167 & 0.0175 & 0.0187 & 0.0713 \\
\hline High school reported GPA & 3.6837 & 3.6333 & 0.4706 & 0.0504 & 0.0600 & 0.0796 & 1.2500 \\
\hline \multirow[t]{3}{*}{ SAT Math } & 608.0851 & 603.0851 & 63.3389 & 5.0000 & 10.000 & 9.4681 & 40.0000 \\
\hline & Mean & eQQ & eQQ & eQQ & \multicolumn{3}{|c|}{ Sample sizes } \\
\hline & difference & med & Mean & $\max$ & & Comparison & Treated \\
\hline Distance & 83.1116 & 83.2843 & 81.2733 & 45.1935 & All & 374 & 94 \\
\hline \multirow{2}{*}{ High school reported GPA } & 82.7007 & 80.0000 & 74.6139 & 0.0000 & Matched & 188 & 94 \\
\hline & & & & & Unmatched & 186 & 0 \\
\hline SAT Math & 91.8211 & 83.3333 & 84.6287 & 55.5556 & Discarded & 0 & 0 \\
\hline
\end{tabular}

eQQ scores represent the median (med), mean, and maximum (max) value of differences between treated and control data for each covariate.

Results of Matching. Results of the two-to-one nearest-neighbor matching were successful (i.e., two comparison cases to one treatment). A total of 282 cases (Hopps, $n=94$; non-Hopps, $n$ = 188) were retained. Before matching, Hopps mean high school GPA scores were 0.3 points higher than the comparison group; after matching, this mean difference was 0.05. Similarly, before matching, Hopps Scholars' math SAT scores were on average 61 points higher than those of the comparison group; after matching, this difference was reduced to 5 points (see Table 1). The matching did not result in the loss of any treatment units. This finalized data set was used to conduct subsequent analyses measuring significant differences between groups.

Sample Population. Table 2 presents descriptive statistics of each group on demographic variables, comparing both the full and matched samples. Likewise, the results include analyses on the full and matched samples to illustrate if and when the relationship holds between groups after matching.

Statistical Analyses. Independent-samples $t$ tests were conducted to examine significant differences between Hopps Scholars and their matched comparisons for academic achievement. Pearson's chi-square test of independence was used for enrollment and institutional classification outcome variables. In instances in which the cell counts for contingency tables are too small to conduct a chi-square test (i.e., fewer than five observed cases), a Fisher's exact $t$ test is used.

\section{RESULTS}

\section{Academic Achievement}

Hopps versus Non-Hopps. Independent-samples $t$ tests tested differences in Morehouse College cumulative GPA between Hopps Scholars and non-Hopps Morehouse STEM students.

TABLE 2. Demographic characteristics

\begin{tabular}{|c|c|c|c|c|}
\hline & \multicolumn{2}{|c|}{ Full comparison group $(n=468)$} & \multicolumn{2}{|c|}{ Propensity matched comparison group $(n=282)$} \\
\hline & Hopps $(n=94)$ & Comparison $(n=374)$ & Hopps $(n=94)$ & Matched comparison $(n=188)$ \\
\hline & Mean (SD) & Mean (SD) & Mean (SD) & Mean (SD) \\
\hline High school GPA ${ }^{\mathrm{a}}$ & $3.68(0.42)$ & $3.39(0.52)$ & $3.68(0.42)$ & $3.63(0.47)$ \\
\hline SAT Math ${ }^{\mathrm{b}}$ & $608(73)$ & $547(86)$ & $608(73)$ & $603(63)$ \\
\hline Morehouse major & \multicolumn{4}{|c|}{ Frequencies \% ( $n$ ) } \\
\hline Applied physics & $4(4)$ & $6(21)$ & $4(4)$ & $7(14)$ \\
\hline Biology & $34(32)$ & $25(92)$ & $34(32)$ & $27(50)$ \\
\hline Chemistry & $12(11)$ & $5(19)$ & $12(11)$ & $7(13)$ \\
\hline Computer science & $10(9)$ & $10(36)$ & $10(9)$ & $10(18)$ \\
\hline General science & $1(1)$ & $8(29)$ & $1(1)$ & $8(15)$ \\
\hline Mathematics & 19 (18) & $9(34)$ & 19 (18) & $11(21)$ \\
\hline Physics & $10(9)$ & $6(24)$ & $10(9)$ & $9(16)$ \\
\hline Pre-engineering & $0(0)$ & $2(7)$ & $0(0)$ & $2(4)$ \\
\hline Psychology & 15 (14) & 32 (119) & 15 (14) & $23(43)$ \\
\hline
\end{tabular}

aWeighted GPA. Scale: 2.69-4.73.

bcale: $200-800$ 
TABLE 3. Cumulative Morehouse GPA comparison

\begin{tabular}{|c|c|c|c|c|c|}
\hline & $n$ & Mean GPA & SD & $t$ & $d f$ \\
\hline \multicolumn{6}{|c|}{ Hopps matched comparison group } \\
\hline Hopps Scholars & 94 & 3.36 & 0.30 & $3.61^{* * *}$ & 236 \\
\hline Matched comparison & 188 & 3.21 & & & \\
\hline \multicolumn{6}{|c|}{ Hopps alumni comparison group } \\
\hline Hopps alumni & 66 & 3.41 & 0.27 & $2.30 *$ & 43 \\
\hline Removed/left Hopps & 28 & 3.25 & 0.34 & & \\
\hline
\end{tabular}

Hopps Scholars had significantly higher GPAs (mean = 3.36) than non-Hopps Morehouse STEM students (mean $=3.21$ ), $t(236)=3.61, p=0.003$.

Alumni versus Participants. Further analysis of the PSM data set also revealed a significant difference between the GPA of Hopps alumni (mean $=3.41$ ) and Hopps participants who left and/or were removed (mean $=3.25$ ) from the program during their time at Morehouse, $t(43),=2.30, p=$ 0.026. Hopps Program alumni have significantly higher Morehouse College GPAs than those who left and/or were removed from the Hopps Program. This finding was expected, however, as participants who were unable to maintain a 3.0 GPA were placed on probation for one semester during which their standing in the Hopps Program was reevaluated. In instances in which participants were unable to raise their GPAs, these former Scholars were officially removed from the program (see Table 3).

\section{Graduate Program Enrollment}

Pearson's chi-square tests (and Fisher's exact tests) of independence were conducted to explore differences in educational attainment between Hopps Scholars and non-Hopps Scholars and between Hopps Alumni and Hopps Participants. Results are summarized for all significant findings. Descriptive statistics for our enrollment outcome variables by Scholar type are presented in Table 4.

\section{All Graduate Programs}

Hopps versus Non-Hopps. In our PSM sample data set, of the 167 Morehouse STEM alumni enrolled in graduate degree programs, 41\% ( $n=69)$ were Hopps Scholars, and 59\% $(n=98)$ were non-Hopps comparison students (Table 4). To determine whether Hopps Scholars were more likely to attend graduate school than their matched peers, we sought to determine whether a relationship exists between overall graduate school enrollment and Hopps Scholar status. The Pearson's chi-square test with Yates' continuity correction ${ }^{8}$ indicates that the association between Scholar status and graduate school enrollment is significant (see Table 5).

The odds ratio tells us that the odds of a Hopps Scholar enrolling in graduate school is 2.53 times higher than if they

${ }^{8}$ Yates continuity correction is appropriate for $2 \times 2$ tables, as Pearson chi-square may increase the chances of producing a type I error (for more on this topic, see Field, 2013). had been a non-Hopps Morehouse STEM graduate. In the sections below, each significant chi-square test statistic is calculated in this manner and explained in terms of the odds or likelihood of success.

Enrollment: STEM Degree Programs. The following analyses explore the extent to which Hopps Scholars enrolled in particular degree programs. That is, we compare Hopps Scholars with comparison students on graduate enrollment in STEM using two definitions of STEM, one broad and one narrow. In the broad definition, we include psychology fields in our definition of STEM; we exclude psychology from the narrow definition. Proportionally speaking, more Hopps Scholars enrolled in graduate programs in STEM than comparison students for both the broad (46\% vs. $34 \%$ ) and narrow (41\% vs. $28 \%$ ) definitions of STEM (see Table 4).

STEM Degrees (Including Psychology): Hopps versus NonHopps. A chi-square test of independence (Table 6) revealed that Hopps Scholars were significantly more likely than comparison students to enroll in graduate STEM programs, $\chi^{2}(1$, $N=282)=14.75, p<0.001$. The odds of a Hopps Scholar enrolling in a graduate STEM program (including psychology) is 2.42 times higher than a non-Hopps Morehouse STEM graduate.

STEM Degrees (Not Including Psychology): Hopps versus Non-Hopps. Hopps Scholars are also significantly more likely to enroll in an advanced STEM degree programs than comparison students, $\chi^{2}(2, N=282)=15.14, p<0.001$. In fact, a Hopps Scholar is 2.53 times more likely than a comparison student to enroll in a graduate STEM degree program. The slightly higher odds ratio for this narrow definition of STEM makes sense given that the Hopps Program stressed participant retention in the physical and natural sciences. See Table 6 for significant graduate school enrollment results.

Health-Related Degrees: Hopps versus Non-Hopps. Pearson chi-square results indicate that Hopps Scholars are no more likely to enroll in medical degree and health-related programs than comparison students (Table 6); however, upon further examination, of those enrolled in a graduate program, proportionally fewer Scholars enrolled in health-related degree programs than comparison students ( $16 \%$ of 69 vs. $22 \%$ of 98 , respectively; Table 4).

Institution Type. To determine whether Hopps Scholars are more likely to attend research-intensive institutions than their non-Hopps STEM Morehouse peers, we created three binary outcome variables comparing master's institutions (with very low research activity) with DRU doctoral-granting institutions (with low research activity), DRU to RU/H doctoral-granting institutions (those with high research activity), and RU/H to $\mathrm{RU} / \mathrm{VH}$ doctoral-granting institutions (those with very high research activity) institutions, respectively (see Table 7). This analysis compares groups of Morehouse STEM graduates: Hopps with non-Hopps and Hopps Alumni with Hopps Participants. Pearson's chi-square tests of independence (or Fisher's exact $t$, where appropriate) were conducted to test for significant differences between groups. 
TABLE 4. Graduate school enrollment: descriptive statistics

\begin{tabular}{|c|c|c|c|c|}
\hline & \multicolumn{4}{|c|}{ Frequencies \% ( $n$ ) by scholar status } \\
\hline & $\begin{array}{l}\text { All Hopps Scholars } \\
(n=94)\end{array}$ & $\begin{array}{l}\text { Hopps Alumni } \\
\quad(n=66)\end{array}$ & $\begin{array}{l}\text { Hopps Participants } \\
\quad(n=28)\end{array}$ & $\begin{array}{c}\text { Non-Hopps comparison } \\
(n=188)\end{array}$ \\
\hline Enrollment: all graduate programs ${ }^{\mathrm{a}}$ & $73(69)$ & $73(48)$ & $75(21)$ & $52(98)$ \\
\hline \multicolumn{5}{|l|}{ By Morehouse major } \\
\hline Applied physics & $4(3)$ & $4(2)$ & $5(1)$ & $3(3)$ \\
\hline Biology & $32(22)$ & $31(15)$ & $33(7)$ & $34(33)$ \\
\hline Chemistry & $12(8)$ & $13(6)$ & $10(2)$ & $11(11)$ \\
\hline Computer science & $7(5)$ & $8(4)$ & $5(1)$ & $9(9)$ \\
\hline General science & $0(0)$ & $0(0)$ & $0(0)$ & $2(2)$ \\
\hline Mathematics & $22(15)$ & $19(9)$ & $29(6)$ & $6(6)$ \\
\hline Physics & $12(8)$ & $10(5)$ & $14(3)$ & $11(11)$ \\
\hline Pre-engineering & $0(0)$ & $0(0)$ & $0(0)$ & $0(0)$ \\
\hline Psychology & $14(10)$ & $17(8)$ & $10(2)$ & $24(24)$ \\
\hline \multicolumn{5}{|l|}{ Enrollment: STEM programs ${ }^{a}$} \\
\hline STEM degrees (with psychology) & $46(32)$ & $44(21)$ & $52(11)$ & $34(33)$ \\
\hline STEM degrees (without psychology) & $41(28)$ & $38(18)$ & $48(10)$ & $28(27)$ \\
\hline Enrollment: health-related programs ${ }^{\mathrm{a}}$ & $16(11)$ & $15(7)$ & $19(4)$ & $22(22)$ \\
\hline MD degrees & $1(1)$ & $2(1)$ & $0(0)$ & $4(4)$ \\
\hline Other degrees & $15(10)$ & $13(6)$ & $19(4)$ & $18(18)$ \\
\hline
\end{tabular}

aAll percentages are calculated using the overall graduate school enrollment values for each Scholar Status category ( $n=69,48,21$, and 98, respectively).

Overall High versus Low Research Institutions: Hopps versus Non-Hopps. Pearson chi-square tests of independence revealed that Hopps scholars are significantly more likely to attend doctoral-granting institutions with high or very high (RU/H or RU/VH) research activity than low research activity (master's and DRU) institutions when compared with comparison students $\chi^{2}(1, N=167)=8.217, p<0.01$. Hopps Scholars are 3.28 times more likely to attend graduate institutions with higher as opposed to lower research activity. However, disaggregating the data revealed additional variations by institution type, as discussed in the following sections (see Table 8).

Master's versus DRU: Hopps versus Non-Hopps. Results also suggest that, although proportionally fewer Hopps Scholars attend master's as opposed to DRU (low research) institutions when compared with non-Hopps comparison students, this difference is not significant ( $p>0.05$; Table 8 ).

$D R U$ versus RU/H: Hopps versus Non-Hopps. On the other hand, Hopps Scholars are significantly more likely to attend high research activity doctoral-granting institutions (RU/H) than low research activity (DRU) doctoral-granting institutions when compared with their non-Hopps comparison students. A Fisher's exact test revealed that this difference was significant $(p<0.01)$ and that Hopps Scholars are 14 times more likely to attend high research activity institutions (RU/H) than DRU

TABLE 5. Enrollment numbers: all graduate programs

\begin{tabular}{lccc}
\hline & Enrolled & Not enrolled & Total \\
\hline Hopps Scholars & $73 \%(69)$ & $27 \%(25)$ & 94 \\
Comparison & $52 \%(98)$ & $48 \%(90)$ & 188 \\
\hline
\end{tabular}

$\chi^{2}(1, N=282)=10.88, p<0.001$. institutions when compared with matched comparison students (Table 8).

$R U / H$ versus RU/VH: Hopps versus Non-Hopps. Finally, although a greater proportion of Hopps scholars attend doctoral institutions with very high research activity (RU/VH), as opposed to high research activity $(\mathrm{RU} / \mathrm{H})$, than their matched comparison students, this difference is not statistically significant ( $p>0.05$; Table 8).

\section{DISCUSSION}

\section{Results Summary}

This paper demonstrates the impact of the Hopps Scholars Program on undergraduate academic performance and graduate enrollment of Morehouse College students. Hopps Scholars consistently outperformed their non-Hopps peers on each outcome variable: undergraduate academic performance, enrollment in graduate STEM programs, and selectivity of graduate school enrollment. After matching, Hopps Scholars earned significantly higher college GPAs at graduation (GPA $=3.36$ vs 3.21 ) ; were 2.5 times more likely to enroll in STEM graduate programs; and were 14 times more likely to attend doctoral research institutions with higher research activity, rather than those with lower research activity, than their STEM peers. This is a unique finding, as we were unable to find another study in the literature that focused on the types of institutions black males attended for graduate school. Taken further, findings indicate that all Hopps Scholars benefited from the assistance they received from the program (financial, coaching and counseling support, and exposure to research), including those who did not complete the program. Overall, the results suggest that Hopps participants persist at a rate higher than that of Morehouse STEM students who did not participate in the Hopps Scholars Program. 
TABLE 6. Graduate school enrollment: significance testing

\begin{tabular}{|c|c|c|c|c|}
\hline & \multicolumn{2}{|c|}{ Scholar status } & \multirow[b]{2}{*}{$\chi^{2}$} & \multirow[b]{2}{*}{$d f$} \\
\hline & $\begin{array}{l}\text { All Hopps Scholars } \\
(n=94)\end{array}$ & $\begin{array}{l}\text { Non-Hopps comparison } \\
\qquad(n=188)\end{array}$ & & \\
\hline \multicolumn{5}{|c|}{ Overall graduate degree program enrollment } \\
\hline Enrolled & $73 \%(69)$ & $52 \%(98)$ & $10.88^{* * *}$ & 1 \\
\hline Not enrolled & $27 \%(25)$ & $48 \%(90)$ & & \\
\hline \multicolumn{5}{|c|}{ STEM graduate degree including psychology program enrollment } \\
\hline Enrolled & $34 \%(32)$ & $18 \%(33)$ & $8.70 * *$ & 1 \\
\hline Not enrolled & $66 \%(62)$ & $82 \%(155)$ & & \\
\hline \multicolumn{5}{|c|}{ STEM graduate degree not including psychology program enrollment } \\
\hline Enrolled & $30 \%(28)$ & $14 \%(27)$ & $8.54 * *$ & 1 \\
\hline Not enrolled & $70 \%(66)$ & $86 \%(161)$ & & \\
\hline \multicolumn{5}{|c|}{ Health-related degree program enrollment } \\
\hline Enrolled & $12 \%(11)$ & $12 \%(22)$ & 0.04 & 1 \\
\hline Not enrolled & $88 \%(83)$ & $78 \%(76)$ & & \\
\hline
\end{tabular}

These positive findings show Hopps significantly enhanced the success of Morehouse STEM students.

\section{Program Design}

To better understand why Hopps participants outperformed their peers, we reviewed several programs with goals similar to those of the Hopps Scholars Program for comparison. While each program is unique, all of them include at least three of the key program components listed in Table 9 (Estrada, 2015). In Hopps, instruction and program activities are designed to be delivered using all seven key program components included in Table 9.

Hopps shares five key program components with the Meyerhoff Scholars Program (i.e., summer pre-freshman program, mentored research experience, program meetings, program coaching and counseling support and financial assistance). The Meyerhoff Scholars Program reports that their underrepresented students were 5.3 times more likely to have graduated from or be currently attending a STEM doctoral or $\mathrm{MD} / \mathrm{PhD}$ program than those students who did not participate in the program at the University of Maryland, Baltimore County (Maton et al., 2012).
However, the Meyerhoff Scholars Program is housed at a public, PWI research university, and its results include statistics on all underrepresented groups (black, Latino/Hispanic, and Asian males and females). Moreover, their data do not disaggregate graduates who entered medical school from those who entered graduate school. Despite these differences, comparison of both programs' components and outcomes support the conclusion that intervention programs of this type are effective in increasing the numbers of underrepresented groups in STEM.

Hopps also shares five key program components with the MARC programs, four with RISE, and four with the Ronald McNair Scholars Program. Data from each intervention suggests that all have been successful in increasing the number of underrepresented students receiving STEM degrees (Garrison and Brown 1985; Maton et al., 2000, 2012; U.S. Department of Education, 2002, 2005; Bejar, 2013; Manzanares, 2015).

The comparison of intervention programs also illustrates that the one unique component of Hopps is the graduate school tours and laboratory site visits. While we have not yet had the opportunity to assess the impact of the individual components of the Hopps Program, we believe these visits were extremely

TABLE 7. Institution type: descriptive statistics

\begin{tabular}{|c|c|c|c|c|}
\hline & Master's \% (n) & DRU \% $(n)$ & $\mathrm{RU} / \mathrm{H} \%(n)$ & RU/VH \% (n) \\
\hline \multicolumn{5}{|l|}{ Hopps matched comparison group } \\
\hline Hopps Scholars $(n=69)$ & $13(9)$ & $1(1)$ & $20(14)$ & $65(45)$ \\
\hline Matched control $(n=98)$ & $26(26)$ & $9(9)$ & $9(9)$ & $55(54)$ \\
\hline Subtotal & 35 & 10 & 23 & 99 \\
\hline \multicolumn{5}{|l|}{ Hopps Alumni comparison group } \\
\hline Hopps alumni $(n=48)$ & $8(4)$ & $2(1)$ & $21(10)$ & $69(33)$ \\
\hline Removed/Left Hopps $(n=21)$ & $24(5)$ & $0(0)$ & $19(4)$ & $57(12)$ \\
\hline Subtotal & 9 & 1 & 14 & 45 \\
\hline
\end{tabular}

All percentages are calculated using sample totals, as opposed to subtotals. Percentages may not sum to 100 due to the effects of rounding. 
TABLE 8. Institution type: significance testing

\begin{tabular}{|c|c|c|c|c|}
\hline & \multicolumn{2}{|r|}{ Scholar status } & \multirow[b]{2}{*}{$\chi^{2}$} & \multirow[b]{2}{*}{$d f$} \\
\hline & Hopps $(n=69)$ & Matched comparison $(n=98)$ & & \\
\hline \multicolumn{5}{|c|}{ Overall high vs. low research institution } \\
\hline High (RU/H and RU/VH) & $86 \%(59)$ & $64 \%(63)$ & $8.21 * * *$ & 1 \\
\hline Low (master's and DRU) & $14 \%(10)$ & $36 \%(35)$ & & \\
\hline \multicolumn{5}{|l|}{ Master's vs. DRU } \\
\hline Master's & $13 \%(9)$ & $27 \%(26)$ & 3.88 & 1 \\
\hline DRU & $1 \%(1)$ & $9 \%(9)$ & & \\
\hline \multicolumn{5}{|l|}{ DRU vs. RU/H ${ }^{\mathrm{a}}$} \\
\hline DRU & $1 \%(1)$ & $9 \%(9)$ & $5.37 * *$ & 1 \\
\hline $\mathrm{RU} / \mathrm{H}$ & $20 \%(14)$ & $9 \%(9)$ & & \\
\hline \multicolumn{5}{|l|}{ RU/H vs. RU/VH } \\
\hline $\mathrm{RU} / \mathrm{H}$ & $20 \%(14)$ & $9 \%(9)$ & 1.21 & 1 \\
\hline RU/VH & $65 \%(45)$ & $55 \%(54)$ & & \\
\hline
\end{tabular}

aresults hold for Fisher's exact $t$.

$* * p<0.01$.

$* * * p<0.001$.

TABLE 9. Key program components in Hopps and other programs

\begin{tabular}{|c|c|c|c|c|c|}
\hline Program component & $\begin{array}{c}\text { Hopps Scholars } \\
\text { Program }\end{array}$ & $\begin{array}{c}\text { Meyerhoff } \\
\text { Scholars Program }\end{array}$ & MARC $^{\mathrm{a}}$ & RISE & $\begin{array}{c}\text { Ronald McNair } \\
\text { Scholars Program }\end{array}$ \\
\hline Summer pre-freshman experience & + & + & - & - & - \\
\hline \multicolumn{6}{|l|}{ Mentored research experience } \\
\hline Summer & + & + & + & + & + \\
\hline Academic year & + & + & + & - & - \\
\hline Program meetings & + & + & + & - & + \\
\hline Graduate school tours and laboratory site visits & + & - & - & - & - \\
\hline Program coaching and counseling & + & + & + & + & + \\
\hline Scientific conference and symposia & + & - & + & + & - \\
\hline Financial assistance & + & + & + & + & + \\
\hline
\end{tabular}

+ , component present in program; -, component absent from program.

aThese components were characteristic of many MARC programs at the time of their evaluation in 1985.

important in that they gave Hopps scholars the opportunity to meet graduate school STEM faculty, discuss graduate school experiences with graduate students, and tour research laboratories related to their fields. These visits also allowed scholars to develop networks and build their networking skills.

\section{Data Limitations and Future Research}

This paper demonstrates promising results on how a program like Hopps can produce positive outcomes for students at a small, liberal arts HBCU; however, there were some factors that limited our ability to fully demonstrate program impact.

PSM reduced the effects of recruitment bias in this study; however, academically talented Morehouse STEM students who did not participate in Hopps may not persist at the same rate as their peers because of a lack of interest in STEM graduate programs or graduate programs in general. On the other hand, it is known that some non-Hopps students participated in intervention programs (HHMI, MARC, RISE, etc.) ${ }^{9}$ aimed at

${ }^{9}$ HHMI: Howard Hughes Medical Institute; NIGMS-MARC/U*STAR: National Institute of General Medical Sciences-Minority Access to Research Careers/Under- increasing the number of African-American males pursuing advanced degrees in STEM. The frequency with which nonHopps students were involved in such programs and, for those involved, the extent to which it impacted their academic outcomes are unknown.

Likewise, there were a limited number of control factors that were available when matching Hopps Scholars with comparison students through institutional records. The population of Morehouse College is relatively homogenous, so factors like race and gender were common across both groups. Instead, we were able to able to control for prior academic achievement, which was the most useful control variable available through institutional records. Other than these factors, there was no other salient information available through institutional records that could be used to control for student background.

Additionally, the majority of U.S. colleges and universities participate in the NSC student tracking system, but not all. It is unknown whether any students were missed entirely (having

graduate Student Training in Academic Research Program; MBRS-RISE: Minority Biomedical Research Support-Research Initiative for Scientific Enhancement. 
gone to a nonparticipating school) or had additional degree or enrollment information that was not in the system. It should be noted that, given the relatively recent graduation dates of most Hopps Scholars (2010 or later), few have had the opportunity to graduate from $\mathrm{PhD}$ programs, which is a major outcome of the program. Likewise, those who graduated from Morehouse more recently (both Hopps and non-Hopps students) have had less time to enroll in graduate school and to have records made available in the NSC system. The creation of a "graduate school enrollment" variable allowed for the best possible proxy for our ideal outcome (completion of STEM PhDs), although we understand that it is not entirely certain that these students will complete their STEM graduate degree programs.

Finally, in instances in which multiple graduate institutions were identified for a single graduate, the Carnegie Classification was taken for all schools, and the student's highest-ranking institution was used. However, given that most students are still in the process of obtaining their final degrees, it is unknown whether the classifications corresponding to their current institutions reflect the ones from which they will actually receive their degrees. For example, some students may have left a higher-ranking institution to attend a lower-ranking institution but are still counted as attending the former based on enrollment alone.

In future work, we propose to conduct additional quantitative and qualitative analyses to identify specific factors (i.e., participant attitudinal and behavioral characteristics) that are most effective at increasing the representation of black males in STEM. In particular, as illustrated by the comparison of programs, we see an obvious need to conduct subsequent studies to determine the impact of individual program components on participant outcomes.

\section{Policy Implications}

This study fills an important gap in the literature by presenting a quantitative examination of persistence in STEM and graduate school enrollment patterns of an HBCU-based STEM intervention effort. In particular, it investigates the effects of a research a training program for black males in STEM at Morehouse College, the only all-male HBCU in the world, and one of the top baccalaureate-origin institutions of black science and engineering doctoral recipients (Burrelli and Rapoport, 2008; NSF, NCES, 2015).

It is well known that black males do not perform as well as their counterparts in STEM and account for a mere 5\% of STEM bachelor's degrees and 2.8\% of STEM doctoral degrees (Bowen et al., 2009; Snyder and Dillow, 2011). Studies have revealed several factors that impact academic performance and retention of underrepresented groups, and specifically black males in STEM (Marks et al., in press, 2016). These factors include low test scores, lack of academic preparation, absenteeism, poor academic counseling, and the cost of higher education (Marks et al., in press, 2016). These findings suggest that intervention programs that focus on these factors have the greatest impact in increasing the academic performance and retention of black males in STEM (Estrada, 2015).

The program design of Hopps includes an emphasis on research as a means of active learning. Involving students in in-depth research allows them to apply what they have learned in the classroom and to develop their problem-solving, critical-thinking, and analytical skills, key goals of a liberal education. The research emphasis included in the Hopps design may serve as a model to enhance student learning at other historically black institutions. This program model can be applied at institutions aiming to increase the number of black males pursuing STEM degrees at all levels.

Even though the graduation rates for underrepresented STEM students have increased, amounts are still far from being representative of percentages in the general U.S. population (Gerald and Haycock, 2006; Estrada, 2015). The results of this study demonstrate the effectiveness of the Hopps Scholars Program. The Hopps Program's focus on academic achievement, coaching and counseling, and consistent exposure to research has resulted in persistence outcomes that exceed those of other similarly prepared and talented Morehouse STEM students. As such, the Dr. John H. Hopps Jr. Defense Research Scholars Program serves as a model for programs committed to increasing the number of African-American males pursuing advanced degrees in STEM.

To reduce gaps in the educational and workforce pathways to STEM careers, continued investment in programs similar to Hopps, particularly those aimed at increasing the representation of black males in STEM, is critical.

In addition to programmatic support, educational institutions should also 1) develop clear educational pathways or bridges involving programs, conferences, and initiatives to improve outcomes for underrepresented groups, especially black males; 2) facilitate curricular partnerships across those educational pathways; and 3) provide faculty with grants that provide opportunities for students to conduct research with them in STEM.

Educational pathways partnerships may improve outcomes for underrepresented groups by providing opportunities for sharing information and resources. These established pathways allow educators to identify areas in which attrition occurs and areas for enhancing success. Pipeline partnerships may also provide opportunities for institutions to incentivize faculty to offer research opportunities for STEM students, especially at HBCUs. These partnerships should also be more attractive to funding agencies (Consortium of Seven Centers, 2014).

Since its inception in 2006, nearly 200 students have participated in the Dr. John H. Hopps Jr. Defense Research Scholars Program, leading to an increase in the number of STEM Morehouse graduates pursuing advanced degrees. Positive findings from this study provide additional evidence of how to facilitate the representation of black males in STEM.

\section{ACKNOWLEDGMENTS}

The authors acknowledge the U.S. Department of Defense, Mrs. Evelyn Kent, and Dr. June Gary Hopps for their continued support of the Dr. John H. Hopps Jr. Defense Research Scholars Program.

\section{REFERENCES}

Allen-Ramdial S-AA, Campbell AG (2014). Reimagining the pipeline: advancing STEM diversity, persistence, and success. BioScience 64, 612-618.

Anderson E, Kim D (2006). Increasing the Success of Minority Students in Science and Technology, Washington, DC: American Council on Education. www.acenet.edu/news-room/Documents/Increasing-the-Success-of -Minority-Students-in-Science-and-Technology-2006.pdf (accessed 24 November 2015) 
Austin PC (2010). Statistical criteria for selecting the optimal number of untreated subjects matched to each treated subject when using many-toone matching on the propensity score. Am J Epidemiol 172, 1092-1097.

Bejar V (2013). UCSD Minority Access to Research Careers (MARC) Program, University of California, San Diego. http://studentresearch.ucsd.edu/ _files/assessment/reports/Experiential-Learning/Academic-Enrichment -Program/MARC-2013-10-22.aspx-30.pdf (accessed 8 December 2015).

Bowen WG, Chingos MM, McPherson MS (2009). Crossing the Finish Line: Completing College at America's Public Universities, Princeton, $\mathrm{NJ}$ : Princeton University Press.

Burrell JO, Fleming L, Fredericks AC, Moore I (2015). Domestic and international student matters: the college experiences of black males majoring in engineering at an HBCU. J Negro Educ 84, 40-55.

Burrelli J, Rapoport A (2008). Role of HBCUs as Baccalaureate-Origin Institutions of Black S\&E Doctorate Recipients (NSF 08-319), Arlington, VA: National Science Foundation.

Campbell PB, Jolly E, Hoey L, Perlman LK (2002). Upping the Numbers: Using Research-Based Decision Making to Increase Diversity in Quantitative Disciplines, Newton, MA: Education Development Center. https:// secure.edc.org/publications/prodview.asp?1490 (accessed 9 December 2015).

Carter FD, Mandell M, Maton KI (2009). The influence of on-campus, academic year undergraduate research on STEM PhD outcomes: evidence from the Meyerhoff Scholarship Program. Educ Eval Policy Anal 31, 441-462.

Chang MJ, Cerna O, Han J, Saenz V (2008). The contradictory roles of institutional status in retaining underrepresented minorities in biomedical and behavioral science majors. Rev High Educ 31, 433-464.

Chang MJ, Sharkness J, Hurtado S, Newman CB (2014). What matters in college for retaining aspiring scientists and engineers from underrepresented racial groups. J Res Sci Teach 51, 555-580.

Chubin DE, May GS, Babco E (2005). Diversifying the engineering workforce. J Eng Educ 94, 73-86.

Cole S, Barber E (2003). Increasing Faculty Diversity: The Occupational Choices of High Achieving Minority Students, Cambridge, MA: Harvard University Press.

Coleman J (1968). The concept of equality of educational opportunity. Harv Educ Rev 38, 7-22

Consortium of Seven Centers (2014). Advancing the success of boys and men of color in education. Chronicle of Higher Education. http://ddce utexas.edu/projectmales/2014/08/recommendations-for-policymakers -advancing-the-success-of-boys-and-men-of-color-in-education (accessed 24 November 2015).

Dorans NJ (1999). Correspondences between ACT and SAT I Scores, New York: College Board.

Dorans NJ (2004). Equating, concordance, and expectation. Appl Psychol Meas 28, 227-246.

Eagan MK, Hurtado S, Chang MJ, Garcia GA (2013). Making a difference in science education: the impact of undergraduate research programs. Am Educ Res J 50, 683-713.

Estrada M (2015). White Paper: Ingredients for Improving the Culture of STEM Degree Attainment with Co-Curricular Supports for Underrepresented Minority Students, Brooklyn, NY: Understanding Interventions.

Fakayode SO, Yakubu M, Adeyeye OM, Pollard DA, Mohammed AK (2014). Promoting undergraduate STEM education at a historically black college and university through research experience. J Chem Educ 91, $662-665$

Field A (2013). Discovering Statistics Using IBM SPSS Statistics, Sage.

Fries-Britt S (2000). Identity development of high-ability black collegians. New Dir Teach Learn 82, 55-65.

Gándara P, Maxwell-Jolly J (1999). Priming the Pump: Strategies for Increasing the Achievement of Underrepresented Minority Undergraduates, New York: College Board. http://research.collegeboard.org/publications/ content/2012/05/priming-pump-strategies-increasing-achievement -underrepresented (accessed 9 December 2015).

Garrison HH, Brown PW (1985). Minority Access to Research Careers: An Evaluation of the Honors Undergraduate Training Program, Washington, DC: National Academies Press.

Gerald D, Haycock K (2006). Engines of Inequality: Diminishing Equity in the Nation's Premier Public Universities. Educ Trust.
Gordon E, Bridglall B (2004). Creating excellence and increasing ethnic minority leadership in science, engineering, mathematics and technology: a study of the Meyerhoff Scholars Program. Connoisseurial Evaluation Report 1-49. Retrieved from www.centerforcsri.org/files/PDF/NCREL/ CreatingExcellence.pdf.

Ho DE, Imai K, King G, Stuart Ea (2011). Matchlt: nonparametric preprocessing for parametric causal inference. J Stat Soft 42, 1-28.

Hrabowski FA, Maton KI (1995). Enhancing the success of African-American students in the sciences: freshman year outcomes. School Sci Math 95, 19-27.

Hunter AB, Laursen SL, Seymour E (2007). Becoming a scientist: the role of undergraduate research in students' cognitive, personal, and professional development. Sci Educ 91, 36-74.

Jones MT, Barlow AEL, Villarejo M (2010). Importance of undergraduate research for minority persistence and achievement in biology. $\mathrm{J}$ High Educ 81, 82-115.

Kendricks KD, Nedunuri KV, Arment AR (2013). Minority student perceptions of the impact of mentoring to enhance academic performance in STEM disciplines. J STEM Educ 14, 38-46.

Leggon CB, Pearson W (2008). Assessing programs to improve minority participation in STEM fields: what we know and what we need to know. In: Doctoral Education and the Faculty of the Future, ed. RG Ehrenberg and CV Kuh, Ithaca, NY: Cornell University Press.

Manzanares M (2015). Minority Access to Research Careers-Undergraduate Student Training for Academic Research (MARC-U*STAR) Program. California State University, Los Angeles. http://web.calstatela.edu/ centers/moreprograms/ustar (accessed 9 December 2015).

Marks BT, Haynes JK, Brown JP (2016). Institutional integration, institutional identity, and degree attainment of black males in STEM attending co-educational and all-men's HBCUs. In: Advancing Educational Outcomes in Science, Technology, Engineering, and Mathematics at Historically Black Colleges and Universities, ed. L Flowers, J Moore, and L Flowers, Lanham, MD: University Press of America (in press).

Maton KI, Hrabowski FA (2004). Increasing the number of African American PhDs in the sciences and engineering: a strengths-based approach. Am Psychol 59, 547-556.

Maton KI, Hrabowski FA, Ozdemir M (2007). Opening an African American STEM program to talented students of all races: evaluation of the Meyerhoff Scholars Program, 1991-2005. In: Charting the Future of College Affirmative Action: Legal Victories, Continuing Attacks, and New Research, ed. G Orfield, P Marin, SM Flores, and LM Garces, Los Angeles, CA: Civil Rights Project at UCLA, 125-155.

Maton KI, Hrabowski FA, Schmitt CL (2000). African American college students excelling in the sciences: college and postcollege outcomes in the Meyerhoff Scholars Program. J Res Sci Teach 37, 629-654.

Maton KI, Pollard S, McDougall Weise T, Hrabowski FA (2012). The Meyerhoff Scholars Program: a strengths-based, institution-wide approach to increasing diversity in science, technology, engineering and mathematics. Mt Sinai J Med 79, 610-623.

May GS, Chubin DE (2003). A retrospective on undergraduate engineering success for underrepresented minority students. J Eng Educ 92, 27-39.

McSherry J (2005, October 5). Challenges persist for minorities and women. Electronic Design. http://electronicdesign.com/archive/challenges-persist -minorities-and-women (accessed 31 August 2015).

Myers CB, Pavel DM (2011). Underrepresented students in STEM: the transition from undergraduate to graduate programs. J Divers High Educ 4(2), 90-105.

Nagda BA, Gregerman SR, Jonides J, von Hippel W, Lerner J (1998). Undergraduate student-faculty research partnerships affect student retention. Rev High Educ 22, 55-72.

National Academy of Sciences, National Academy of Engineering, and Institute of Medicine (2011). Expanding Underrepresented Minority Participation: America's Science and Technology Talent at the Crossroads, Washington, DC: National Academies Press.

National Science Foundation, National Center for Science and Engineering Statistics (2015). Top baccalaureate institutions of black S\&E doctorate recipients: 2008-12. In: Women, Minorities, and Persons with Disabilities in Science and Engineering: 2015 (Special Report NSF 15-311). Arlington, VA www.nsf.gov/statistics/2015/nsf15311/tables/pdf/tab7-10.pdf (accessed 9 December 2015). 
Nguyen T-HP (2015). Exploring historically black college and universities ethos of racial uplift: STEM students' challenges and institutions' practices for cultivating learning and persistence in STEM. PhD Thesis, Philadelphia: University of Pennsylvania.

Owens EW, Shelton AJ, Owens BEW, Shelton AJ, Bloom CM, Cavil JK (2012) The significance of HBCUs to the production of STEM graduates: answering the call. Educ Found 26, 33-47.

Pender M, Marcotte DE, Sto Domingo MR, Maton KI (2010). The STEM pipeline: the role of summer research experience in minority students' Ph.D. aspirations. Educ Policy Anal Arch 1830, 1-36.

Perna LW, Gasman M, Gary S, Lundy-Wagner V, Drezner ND (2010). Identifying strategies for increasing degree attainment in STEM: lessons from minority-serving institutions. New Dir Inst Res 2010(148), 41-51.

President's Council of Advisors on Science and Technology (2012). Engage to Excel: Producing One Million Additional College Graduates with Degrees in Science, Technology, Engineering, and Mathematics. Report to the President, Washington, DC: U.S. Government Office of Science and Technology

Randolph JJ, Falbe K, Manuel AK, Balloun JL (2014). A step-by-step guide to propensity score matching in $\mathrm{R}$ information on the data set used. Pract Assess Res Eval 1918, 1-6
RStudio Team (2015). RStudio: Integrated Development for R, Boston, MA: RStudio. www.rstudio.com (accessed 1 November 2015)..

Russell SH, Hancock MP, McCullough J (2007). Benefits of undergraduate research experiences. Science 316, 548-549.

Schultz PW, Hernandez P, Woodcock A, Estrada M, Chance R, Aguilar M, Serpe $R$ (2011). Patching the pipeline: reducing educational disparities in the sciences through minority training programs. Changes 33, 1-27.

Seymour E, Hewitt NM (2000). Talking about Leaving: Why Undergraduates Leave the Sciences, Boulder, CO: Westview.

Snyder TD, Dillow SA (2011). Digest of Education Statistics 2010 (NCES 2011 015), Washington, DC: National Center for Education Statistics.

Toven-Lindsey B, Levis-Fitzgerald M, Barber PH, Hasson T (2015). Increasing persistence in undergraduate science majors: a model for institutional support of underrepresented students. CBE Life Sci Educ 14, ar12.

U.S. Department of Education (2002). A Profile of the Ronald E. McNair Postbaccalaureate Achievement Program: 1999-2000 through 2001-2002, Washington, DC: Office of Postsecondary Education.

U.S. Department of Education (2005). A Profile of the Ronald E. McNair Postbaccalaureate Achievement Program: 1997-1998 through 2001-2002 Washington, DC: Office of Postsecondary Education. 